\title{
Efficacy of Low Level Laser Therapy on Wound Healing in Patients with Chronic Diabetic Foot Ulcers-A Randomised Control Trial
}

\author{
Basavaraj M. Kajagar • Ashok S. Godhi • \\ Archit Pandit • S. Khatri
}

Received: 7 April 2011 / Accepted: 21 December 2011 /Published online: 11 April 2012

(C) Association of Surgeons of India 2011

\begin{abstract}
Foot ulcers are serious complications of Diabetes Mellitus (DM) and are known to be resistant to conventional treatment. They may herald severe complications if not treated wisely. Electromagnetic radiations in the form of photons are delivered to the ulcers in laser form to stimulate healing. This study was conducted to evaluate the efficacy of Low Level Laser Therapy (LLLT) in diabetic ulcer healing dynamics. To determine mean percentage reduction of wound area in study and control groups. Settings: KLES Dr. Prabhakar Kore Hospital and Medical Research Centre, Belgaum. Study Design: Randomized-Control Study. Methods: A total of 68 patients with Type 2 DM having Meggitt-Wagner Grade I foot ulcers of atleast more than 4 weeks duration, less than $6 \times 6 \mathrm{~cm}^{2}$ with negative culture were studied. Patients were randomized into two groups of 34 each. Patients in study group received LLLT with conventional therapy and those in control group were treated with conventional therapy alone. Healing or percentage reduction in ulcer area over a period of 15 days after commencement of treatment was recorded. Statistical Analysis: Unpaired Student $T$ Test and Mann Whitney $U$ test. Mean age of the patients was 50.94 years in control group and 54.35 years in study group $(p=0.065)$. There was no significant difference between control and study group with respect to mean FBS and HbAlc levels ( $p>0.05)$, suggesting
\end{abstract}

B. M. Kajagar $(\bowtie) \cdot$ A. S. Godhi $\cdot$ A. Pandit

Department of Surgery, Jawaharlal Nehru Medical College,

Nehru Nagar,

Belgaum 590010 Karnataka, India

e-mail: bmkajagar@rediffmail.com

S. Khatri

KLE'S College of Physiotherapy,

Nehru Nagar,

Belgaum 590010 Karnataka, India no biochemical differences between two groups. Initial ulcer area was $2608.03 \mathrm{~mm}^{2}$ in study group and $2747.17 \mathrm{~mm}^{2}$ in control group $(p=0.361)$. Final ulcer area was $1564.79 \mathrm{~mm}^{2}$ in study group and $2424.75 \mathrm{~mm}^{2}$ in control group $(p=0.361$ ). Percentage ulcer area reduction was $40.24 \pm 6.30 \mathrm{~mm}^{2}$ in study group and $11.87 \pm 4.28 \mathrm{~mm}^{2}$ in control group $(p<0.001, Z=$ 7.08). Low Level Laser Therapy is beneficial as an adjunct to conventional therapy in the treatment of diabetic foot ulcers (DFU).

Keywords Adjuvant therapies · Diabetic foot ulcers . Low Level Laser Therapy (LLLT) · Wound healing

\section{Introduction}

The number of cases of diabetes mellitus (DM) worldwide is estimated to be around 150 million. This is predicted to double by 2025 with the greatest number of cases in China and India [1,2]. Diabetic foot ulcer (DFU) is a serious complication of DM and is the single most important risk factor for lower limb amputations. More than $60 \%$ of all non-traumatic lower limb amputations are due to DFU complications [3]. Risk factors for DFUs include males, DM of more than 10 years' duration, peripheral neuropathy, abnormal foot structure, peripheral arterial disease, smoking, previous history of ulcers or amputations, and poor glycaemic control. About $15 \%$ of patients with DM are likely to develop foot ulcers during their lifetime and about 6-40\% of them may require an amputation [4].

Although the fundamental pathophysiological factors leading to DFUs remain incompletely understood, the triad of neuropathy, ischaemia, and infections is commonly considered the most important [5]. These ulcers show decrease in both angiogenic response and deficient growth factors 


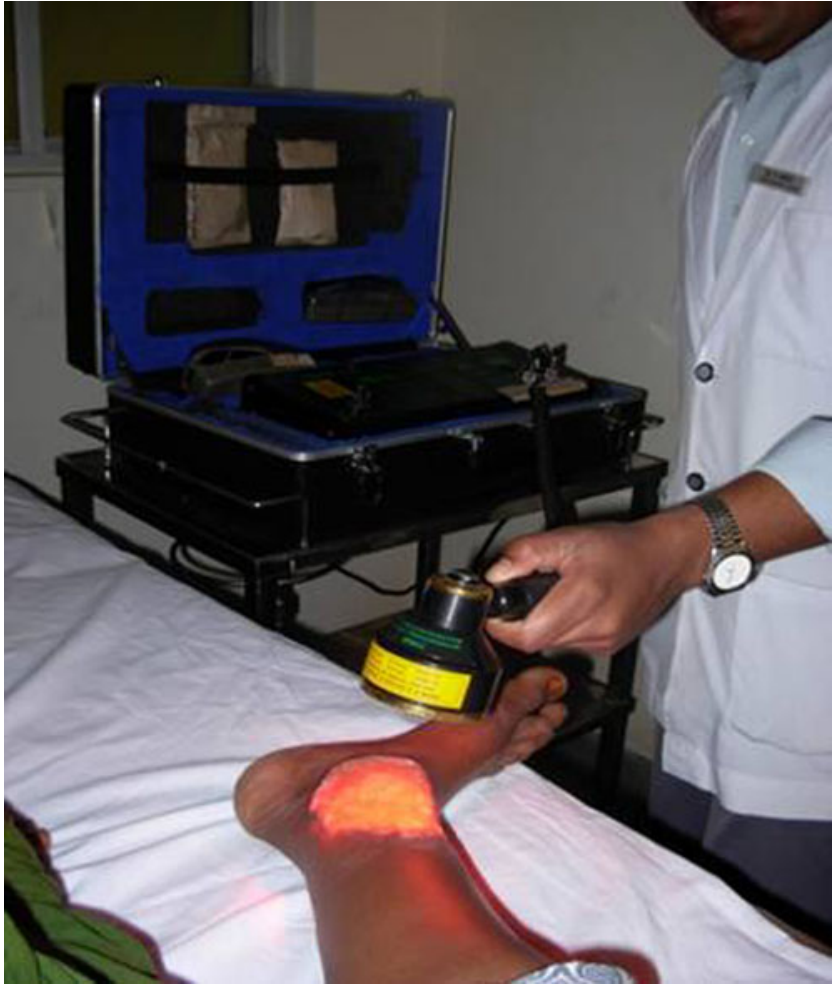

Fig. 1 An LLLT device with a multidiode cluster probe (Thor International Ltd) used in the study

resulting in delayed healing [6]. Non-healing DFUs are resistant to conventional treatment [7]. Several adjuvant therapies which have been tried to stimulate healing process are ultrasound, laser therapy, and other forms of photobiomodulation,

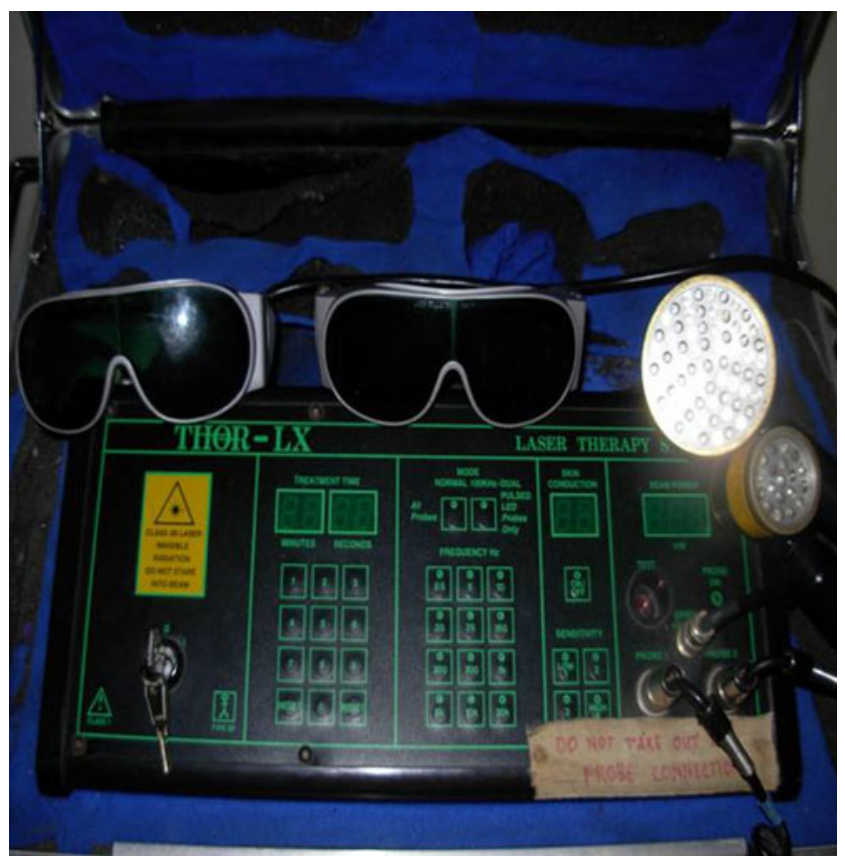

Fig. 2 An LLLT cluster probe being used to treat foot ulcers
Table 1 Demographic characteristics

\begin{tabular}{lll}
\hline Characteristic & $\begin{array}{l}\text { Control group } \\
(n=34)\end{array}$ & $\begin{array}{l}\text { Study group } \\
(n=34)\end{array}$ \\
\hline $\begin{array}{l}\text { Male-female ratio } \\
\text { Mean age (years) }\end{array}$ & $2: 1$ & $2: 1$ \\
Occupation & $50.94 \pm 8.11$ & $54.35 \pm 6.84$ \\
Farmer & & \\
Housewife & $15(44 \%)$ & $16(47 \%)$ \\
Employed & $13(38 \%)$ & $12(35 \%)$ \\
Onset & $6(18 \%)$ & $6(18 \%)$ \\
Insidious/spontaneous & & $11(32 \%)$ \\
Traumatic & $11(32 \%)$ & $23(68 \%)$ \\
Duration of ulcer at presentation & 4 weeks & 5 weeks \\
\hline
\end{tabular}

electrical stimulation, hyperbaric oxygen, and vacuumassisted closure $[8,9]$.

Low-level laser therapy (LLLT) also called low-intensity laser therapy (LILT) or low-energy photon therapy (LEPT) has received clearance from the United States Food and Drug Administration. The clinical efficacy of LLLT in wound healing has been reported [10]. It has been found to significantly decrease the time of wound healing $[11,12]$.

We conducted a study to assess the efficacy of LLLT in Indian patients with chronic DFUs [13].

\section{Materials and Methods}

This study was conducted over a period of 2 years from February 2008 to February 2010 at a tertiary level teaching hospital after obtaining ethical clearance from Institutional Ethics Committee. Type 2 DM patients with MeggittWagner grade I DFUs of at least 4 weeks' duration were included. Those with clinical signs of ischaemia and ankle brachial pressure index (ABI) less than 0.9 were excluded from the study. Sample size was 68. Patients were randomised into two groups of 34 each on the basis of computergenerated numbers. The nature of therapy to be given was topically explained to the patients and written informed consent was obtained from them before enrolment.

Table 2 Risk factors for diabetic foot ulcers

\begin{tabular}{lll}
\hline Risk factors & $\begin{array}{l}\text { Control group } \\
(n=34)\end{array}$ & $\begin{array}{l}\text { Study group } \\
(n=34)\end{array}$ \\
\hline Male sex & $21(61.76 \%)$ & $22(64.47 \%)$ \\
DM duration $>10$ years & $09(26.47 \%)$ & $07(20.58 \%)$ \\
Peripheral neuropathy & $06(17.64 \%)$ & $09(26.47 \%)$ \\
Smoking & $04(11.76 \%)$ & $06(17.64 \%)$ \\
\hline
\end{tabular}


Table 3 Ulcer characteristics

\begin{tabular}{llll}
\hline Clinical features & Control group $(n=34)$ & Study group $(n=34)$ & Statistical significance \\
\hline Initial ulcer area $\left(\mathrm{mm}^{2}\right)$ & $2747.17 \pm 603.79$ & $2608.03 \pm 683.14$ & $p=0.361$ \\
Site of the ulcer & $20(59 \%)$ & $18(53 \%)$ & $p=0.625$ \\
Plantar & $14(41 \%)$ & $16(47 \%)$ & - \\
Dorsum & $\mathrm{I}$ & $\mathrm{I}$ & - \\
Meggitt-Wagner grade & 5 & - \\
Depth of ulcer $(\mathrm{mm})$ & 5 & & \\
\hline
\end{tabular}

All patients were admitted to the surgical ward and were subjected to detailed evaluation. A complete haemogram and renal and liver function tests were carried out in all patients. Patients with fasting blood sugar (FBS) levels measured on two occasions $24 \mathrm{~h}$ apart between 90 and $200 \mathrm{mg} / \mathrm{dL}$ with glycosylated haemoglobin (HbAlc) levels between $6 \%$ and $9 \%$ were included. Ulcer area was calculated by obtaining the impression of ulcer floor on a sheet of cellophane paper and then transferring the imprint onto a graph paper. The ulcer size was measured on day 0 and day 15. Patients with evidence of slough were subjected to repeated surgical debridement before starting the treatment. Objective assessment of vascularity was done by careful palpation of peripheral pulses and calculation of ABI. Colour Doppler imaging of the arterial circulation of lower limbs was performed in patients with feeble or absent pulsations. Presence of osteomyelitis was determined with the help of plain radiographs and they were excluded from the study.

Systemic antibiotics were administered based on culture sensitivity reports. Insulin/oral hypoglycaemic agents (OHA) as advised by the physician/endocrinologist were used to maintain a good glycaemic control. Once adequate glycaemic and infection control had been achieved, LLLT was commenced.

Patients in the study group received treatment with LLLT along with conventional or standard therapy, and those in control group received only conventional treatment in the form of daily wet saline or betadine dressings, antibiotic treatment, contact cast immobilization and slough excision as and when required. An LLLT device with a multidiode cluster probe (Thor International Ltd) (Fig. 1) was used in the study [8]. Figure 2 shows an LLLT cluster probe being used to treat foot ulcers. On the basis of the ulcer size, the duration of exposure was calculated to deliver $2-4 \mathrm{~J} / \mathrm{cm}^{2}$ at
$60 \mathrm{~mW}, 5 \mathrm{kHz}$, daily for 15 days. The ulcer floor and edge were irradiated. The ulcer was then covered with conventional moist dressing.

Pressure off-loading was carried out in patients with plantar ulcers. Healing or per cent reduction in the size of the ulcer over a period of 15 days after commencement of LLLT was recorded as the end point of the study. Simultaneously, these patients were also educated about various aspects of DM including dietary restrictions, exercise, and foot care in order to prevent recurrence. Statistical analysis of data was carried out using standard ' $t$ test', and $p$ value was calculated. Both the patients and administrators wore laser safety goggles to prevent damage to their eyes.

\section{Results}

A total of 68 patients were included in the study. Male to female ratio was $3: 1$. Mean age of the patients was 50.94 years in the control group and 54.35 years in the study group. No significant difference was found between two groups in the demographic characteristics and risk factors as summarized in Tables 1 and 2.

The mean FBS levels among controls were $129.80 \pm$ $3.42 \mathrm{mg} / \mathrm{dL}$ (range $90-172 \mathrm{mg} / \mathrm{dL}$ ) and $120.50 \pm 4.51$ (range $90-187 \mathrm{mg} / \mathrm{dL})$ in the study group $(p=0.105)$. The mean HbAlc levels in the control group were $7.39 \pm 0.05$ (range $6.9-8 \%$ ) and $7.42 \pm 0.05$ (range 7-8\%) in the study group $(p=0.686)$, suggesting no biochemical differences between two groups.

Median duration of ulcer at the time of enrolment in the study was 4 weeks in control and 5 weeks in study groups. Median duration of oral hypoglycaemic agents intake was 10 years in the control group and 5 years in the study group

Table 4 Outcome of the study

\begin{tabular}{lllll}
\hline Results & Control group $(n=34)$ & Study group $(n=34)$ & Statistical significance & 95\% confidence interval \\
\hline Initial ulcer area $\left(\mathrm{mm}^{2}\right)$ & $2747.17 \pm 603.79$ & $2608.03 \pm 683.14$ & $p=0.361$ & - \\
Final ulcer area $\left(\mathrm{mm}^{2}\right)$ & $2424.75 \pm 551.26$ & $1564.79 \pm 437.30$ & $p=0.218$ & - \\
Mean reduction in ulcer area $\left(\mathrm{mm}^{2}\right)$ & $322.44 \pm 85.84$ & $1043.20 \pm 266.62$ & $p<0.010$ & $624.91-816.73$ \\
\hline
\end{tabular}


$(p=0.51)$, while that of insulin intake was 6.5 months in the control group and 4 months in the study group.

Mean initial size of the ulcer was $2747.17 \mathrm{~mm}^{2}$ in the control group and $2608.03 \mathrm{~mm}^{2}$ in the study group $(p=0.361)$. All ulcers in both groups belonged to Meggitt-Wagner grade I and had a depth of $5 \mathrm{~mm}$. There was no significant difference between the two groups (Table 3).

After completion of 15 days of therapy, the final area was $2424.75 \mathrm{~mm}^{2}$ in the control group and $1564.79 \mathrm{~mm}^{2}$ in the study group $(p=0.218)$. Mean reduction in ulcer area was $322.44 \pm 85.84 \mathrm{~mm}^{2}$ in the control group and 1043.20土 $266.62 \mathrm{~mm}^{2}$ in the study group, and this difference between the two groups was statistically significant $(p<0.010)(95 \%$ confidence interval $=624.91-816.73)($ Table 4).

\section{Discussion}

Diabetic foot ulcers pose a major healthcare problem as a significant cause of morbidity, mortality, and financial burden [14]. The healing process in DFUs is arrested in the stage of inflammation, and it is not known why it does not progress further. Decades of intense research have not unravelled the mystery of wound healing completely. However, it is evident that wound healing involves several biological processes at cellular and molecular levels. The research on wound healing targets the cellular and subcellular biomodulation [15-19]. The healing properties of LLLT are likely to be due to photobiomodulation resulting in increased granulation tissue, fibroblast proliferation, collagen synthesis, neovascularization, and early epithelialization, the important changes observed in LLLT-treated wounds. Low doses of laser are stimulative and higher doses are suppressive. Among the various non-invasive treatment modalities, LLLT is gaining increasing interest. Research findings to date based on animal, human, and in vitro studies have shown that LLLT can play a useful role in healing chronic diabetic ulcers resistant to conventional treatment [20-28].

A study by Hopkins et al. has reported results in 22 healthy subjects and shown $55 \%$ greater wound contraction in cases as compared to controls [29]. Gupta et al. have demonstrated a significantly greater reduction $(p<0.002)$ in the surface area of leg ulcers treated with red light and infrared light than in sham-irradiated controls. The leg ulcers were given three treatments per week for 10 weeks, by which time LLLT-treated ulcers showed an average reduction in surface area of $193.0 \mathrm{~mm}^{2}$, whereas in controls it was only $14.7 \mathrm{~mm}^{2}$ [30].

In our study, 34 ulcers treated with LLLT showed significant reduction in percentage wound area, that is, 40.24 \pm $6.30 \mathrm{~mm}^{2}$ compared to $11.87 \pm 4.28 \mathrm{~mm}^{2}$ in control groups
( $p<0.001, Z=7.08$ ). These results show significant benefit following the use of LLLT.

In conclusion, the wounds in subjects treated with LLLT contracted significantly more than the wounds in the nontreated group $(40.24 \%$ vs $11.87 \%, p<0.001)$, which indicates that LLLT is an effective modality to facilitate wound contraction in patients suffering from diabetes and can be used as an adjunct to conventional mode of treatment (dressings and debridement) for healing of diabetic wounds.

\section{References}

1. Aboderin I, Kalache A, Ben-Shlomo Y, Lynch JW, Yajnik CS, Kuh D et al (2001) Life course perspectives on coronary heart disease, stroke and diabetes: key issues and implications for policy and research. World Health Organization, Geneva

2. Bal A, Das AK, Pendsey S, Suresh KR, Vishwanathan V, Ambardekar P (2005) Handbook of diabetic foot care. Diabetic Foot Society of India, Bangalore

3. Brem H, Sheehan P, Rosenberg HJ, Schneider JS, Boulton AJ (2006) Evidence-based protocol for diabetic foot ulcers. Plast Reconstr Surg 117(7):193S-209S

4. Centre for Disease Control and Prevention (2002) National diabetes fact sheet: general information and national estimates on diabetes in the United States, 2002. US Dept of Health and Human Services, Atlanta

5. Eldor R, Raz I, Ben Yehuda A, Boulton AJ (2004) New and experimental approaches to treatment of diabetic foot ulcers: a comprehensive review of emerging treatment strategies. Diabet Med 21(11):1161-1173

6. Steed DL (1997) The role of growth factors in wound healing. Surg Clin N Am 77:575-586

7. Millington JT, Norris TW (2000) Effective treatment strategies for diabetic foot wounds. J Fam Pract 49(11):S40-S48

8. Dyson M (2007) Adjuvant therapies; ultrasound, laser therapy, electrical stimulation, hyperbaric oxygen and VAC-therapy. In: Morrison MJ, Moffatt CJ, Franks PJ (eds) Leg ulcers: a problembased learning approach. Mosby, Elsevier, Philadelphia, pp 429 451

9. Rinaldi F, Alberetto M, Pontiroli A (1993) The diabetic foot. General considerations and proposal of a new therapeutic and preventive approach. Diabetes Res Clin Pract 21(1):43-49

10. Baxter GD (1994) Therapeutic lasers: theory and practice. Churchill Livingstone, Edinburgh

11. Ferney R, Mauro T (1999) Using lasers in diabetic wound healing. Diabetes Technol Ther 1(2):189-192

12. Van Damme H, Limet R (2005) The diabetic foot. Rev Med Liege 60(5-6):516-525

13. Armstrong DG (2002) Clinical examination of diabetic foot and identification of at risk patient. In: Morrison MJ, Moffatt CJ, Franks PJ (eds) Leg ulcers: a problem-based learning approach. Mosby, Elsevier, Philadelphia, pp 163-176

14. Shobhana R, Rama Rao P, Lavanya A, Viswanathan V, Ramachandra A (2000) Cost burden to diabetic patients with foot complications - a study from southern India. JAPI 48:1147-1150

15. Boulton M, Marshall J (1986) He-Ne laser stimulation of human fibroblast proliferation and attachment in vitro. Laser Life Sci $1: 125-134$

16. Landau Z, Schattner A (2001) Topical hyperbaric oxygen and low energy laser therapy for chronic diabetic foot ulcers resistant to conventional treatment. Yale J Biol Med 74(2):95-100 
17. Schindl A, Heinze G, Schindl M, Pernerstorfer-Schon H, Schindl L (2002) Systemic effects of low-intensity laser irradiation on skin microcirculation in patients with diabetic microangiopathy. Microvasc Res 64(2):240-246

18. Pereira AN, Eduardo Cde P, Matson E, Marques MM (2002) Effect of low power laser irradiation on cell growth and procollagen synthesis of cultured fibroblasts. Laser Surg Med 31:263-267

19. Dyson M, Young S (1986) Effect of laser therapy on wound contraction and cellularity in mice. Lasers Med Sci 1:126-130

20. Brem H, Sheehan P, Boulton AJM (2004) Protocol for treatment of diabetic foot ulcers. Am J Surg 187(5A):1S-10S

21. Schindl M, Kerschan K, Schindl A, Schon H, Heinzl H, Schindl L (1999) Induction of complete wound healing in recalcitrant ulcers by low-intensity laser irradiation depends on ulcer cause and size. Photodermatol Photoimmunol Photomed 15(1):18-21

22. Maiya GA, Kumar P, Rao L (2005) Effect of low intensity heliumneon $(\mathrm{He}-\mathrm{Ne})$ laser irradiation on diabetic wound healing dynamics. Photomed Laser Surg 23(2):187-190

23. Basford C (1989) Low energy laser therapy: controversies and new research findings. Lasers Surg Med 9:1-5
24. Haas AF, Isseroff RR, Wheeland RG, Rood PA, Graves PJ (1990) Low energy helium-neon laser irradiation increases the motility of human keratinocytes. J Invest Dermatol 94:822-826

25. Yu W, Naim JO, Lanzafame RJ (1994) The effects of photoirradiation on the secretion of TGF and PDGF from fibroblasts in vitro. Laser Surg Med Suppl 6:8

26. Schindl A, Schindl M, Schon H, Knobler R, Havelec L, Schindl L (1998) Low-intensity laser irradiation improves skin circulation in participants with diabetic microangiopathy. Diabetes Care 21 (4):580-584

27. Medrado AR, Pughese LS, Reis SR, Andrade ZA (2003) Influence of low level laser therapy on wound healing and its biological action on myofibroblasts. Laser Surg Med 32:179-184

28. Koutam M, Janisch R, Veselska R (2003) Effects of low power laser irradiation on cell proliferation. Scr Med 73(3):163-172

29. Hopkins J, Todd A, Jeff G, Seegmiller G, Baxter D (2004) Low level laser therapy facilitates superficial wound healing in humans: a triple-blind, sham-controlled Study. J Athl Train 39(3):223-229

30. Gupta AK, Filonenko N, Salansky N, Sadder DN (1998) The use of low energy photon therapy (LEPT) in venous leg ulcers: a double blind, placebo-controlled study. Dermatol Surg 24:1383-1386 